\title{
Requirement of Stat3 but not Stat1 Activation for Epidermal Growth Factor Receptor-mediated Cell Growth In Vitro
}

\author{
Jennifer Rubin Grandis, ${ }^{\star}$ Stephanie D. Drenning, ${ }^{\star}$ Arup Chakraborty, ${ }^{\ddagger}$ Min-Yu Zhou, ${ }^{\star}$ Qing Zeng, ${ }^{\star}$ Allyson S. Pitt, ${ }^{\star}$ \\ and David J. Tweardy $\S^{\star}$ \\ $*$ Department of Otolaryngology, ${ }^{\ddagger}$ Department of Medicine, and ${ }^{\S}$ Department of Molecular Genetics and Biochemistry, University of \\ Pittsburgh School of Medicine and the University of Pittsburgh Cancer Institute, Pittsburgh, PA 15213
}

\begin{abstract}
Stimulation of epidermal growth factor receptor (EGFR) by ligand(s) leads to activation of signaling molecules including Stat1 and Stat3, two members of the signal transducers and activators of transcription (STAT) protein family. Activation of Stat1 and Stat3 was constitutive in transformed squamous epithelial cells, which produce elevated levels of TGF- $\alpha$, and was enhanced by the addition of exogenous TGF- $\alpha$. Targeting of Stat3 using antisense oligonucleotides directed against the translation initiation site, resulted in significant growth inhibition. In addition, cells stably transfected with dominant negative mutant Stat3 constructs failed to proliferate in vitro. In contrast, targeting of Stat1 using either antisense or dominant-negative strategies had no effect on cell growth. Thus, TGF- $\alpha /$ EGFR-mediated autocrine growth of transformed epithelial cells is dependent on activation of Stat3 but not Stat1. (J. Clin. Invest. 1998. 102:1385-1392.) Key words: growth factor receptor • signal transduction $\bullet$ proliferation $\cdot$ growth arrest $\cdot$ squamous cell carcinoma
\end{abstract}

\section{Introduction}

Elevated TGF- $\alpha$ and epidermal growth factor receptor $(\text { EGFR })^{1}$ mRNA and protein expression levels have been detected in transformed squamous epithelium compared with levels in normal mucosa (1-3). Overexpression of TGF- $\alpha$ and EGFR is accompanied by increased EGFR activity, which is coupled to transformation and proliferation of squamous epithelial cells $(4,5)$. Studies specifically targeting EGFR kinase activity have demonstrated inhibition of transformed but not normal squamous epithelial cell proliferation (6).

The precise mechanisms by which growth factor-induced cell surface signals are transmitted to the nucleus and ultimately result in cell division are only partially understood. In

This study was first reported as an abstract. Proceedings of the American Association of Cancer Research. 1997. 38:374.

Address correspondence to Jennifer Rubin Grandis, The Eye and Ear Institute, Suite 500, 200 Lothrop Street, Pittsburgh, PA 15213. Phone: 412-647-5280; FAX: 412-647-2080; E-mail: jgrandis@vms.cis. pitt.edu

1. Abbreviations used in this paper: EGFR, epidermal growth factor receptor; EMSA, electrophoretic mobility shift assay; hSIE, high affinity serum-inducible element.

J. Clin. Invest.

(C) The American Society for Clinical Investigation, Inc. 0021-9738/98/10/1385/08 \$2.00

Volume 102, Number 7, October 1998, 1385-1392

http://www.jci.org response to ligands, including TGF- $\alpha$, the EGFR dimerizes and becomes phosphorylated on multiple tyrosine residues. These phosphotyrosines, in turn, allow the activated receptor to associate with other signaling proteins. Several EGFR signaling intermediates have been described including ras/MAP kinase, phosphatidylinositol-3-kinase (PI-3-kinase), and phospholipase $\mathrm{C} \gamma$ (PLC $\gamma$ ). However, there is little evidence that targeting of these downstream intermediates results in inhibition of proliferation. EGFR has also been demonstrated to activate STATs (7-9), proteins that serve the dual function of signal transducers and activators of transcription (10-11). To date, seven STATs have been identified: $1-4,5$ a, 5 b, and 6 .

Several reports suggest a link between activation of STAT protein and uncontrolled proliferation. There is enhanced DNA-binding activity of a Stat3-related protein in cells transformed by the v-Src oncoprotein $(12,13)$, and Stat1 activation has been associated with the transformed state induced by v-Eyk (14). Less direct evidence includes the observations that: a) breast cancer samples have higher levels of STAT-binding activity compared with benign lesions or normal breast epithelium (15); $b$ ) newly established breast cancer cell lines demonstrate constitutively active Stat 3 homodimers (16); and $c$ ) activation of Stat $3 \alpha$ may contribute to the failure of some AML cells to differentiate in response to G-CSF(17). No previous study has examined the effect of downmodulation of STAT proteins on transformation or proliferation, or established the causes of the increased STAT activity detected in human tumors.

\section{Methods}

Cells. Cell lines derived from patients with squamous cell carcinoma of the head and neck (SCCHN) were grown in DME (Cellgro, Washington, DC). With 15\% FBS (GIBCO Laboratories, Grand Island, $\mathrm{NY}$ ), plus $100 \mathrm{U} / \mathrm{ml}$ of penicillin and $100 \mathrm{U} / \mathrm{ml}$ of streptomycin (GIBCO) (18). The majority of SCCHN cell lines are part of a large collection established in the Department of Otolaryngology at the University of Pittsburgh (19). SCC 66 was a generous gift from Suzanne Gollin (University of Pittsburgh, Pittsburgh, PA). The human hepatoma cell line, HepG2, was grown as described (20). Normal mucosal epithelial cells were obtained from primary cultures established using oropharyngeal mucosa harvested from patients undergoing non-oncologic head and neck procedures as described previously (21).

Reagents. rh-TGF- $\alpha$ was obtained from Calbiochem/Oncogene Science (Cambridge, MA). Complementary duplex oligonucleotides were synthesized based on the published sequences of STAT DNAbinding elements with the addition of GATC at the $5^{\prime}$ termini to allow radiolabeling as described previously (22). The EGFR-specific tyrosine kinase inhibitor, PD153035, was kindly provided by David Fry (23). The TGF- $\alpha-$ neutralizing antibody was obtained from Oncogene Science (Cambridge, MA; Ab\#3).

Antisense oligodeoxynucleotide studies. Phosphorothioated 21-mer oligodeoxynucleotides were synthesized on an Applied Biosystem 394 synthesizer by means of $\beta$-cyanothylphysphoramidite chemistry 
to minimize degradation of the oligonucleotides by endogenous nucleases. We have previously determined the optimum conditions for oligonucleotide uptake by SCCHN cells via end labeling followed by measuring counts in nuclear and cytoplasmic fractions of cell lysates ( $\sim 40 \%$ uptake in nucleus by $24 \mathrm{~h}$ ) (24). The antisense oligonucleotides were directed against the translation start site (AUG codon) and surrounding nucleotides of the human Stat3 gene (25) and Stat1 gene (26). Stat 3 antisense oligonucleotide sequence was $5^{\prime}$ CCATTGGGCCATCCTGTTTCT $3^{\prime}$ and the corresponding sense oligonucleotide sequence was 5' AGAAACAGGATGGCCCAATGG 3'. The Stat 1 antisense oligonucleotide sequence was $5^{\prime}$ CCACTGAGACATCCTGCCACC $3^{\prime}$ and the corresponding sense oligonucleotide sequence was 5' GGTGGCAGGATGTCTCAGTGG 3'.

To examine the effect of antisense oligonucleotide treatment on SCCHN cell growth, cells were plated at a density of $10^{4}$ cells/microtiter well in 24-well polystyrene plates (Falcon Plastics, Cockeysville, $\mathrm{MD})$. After $24 \mathrm{~h}$, at which point the cells had reached $30-40 \%$ confluency, $250 \mu \mathrm{l}$ of fresh culture medium containing $12.5 \mu \mathrm{M}$ antisense oligonucleotide targeted against the translation start site of human Stat $3 \alpha / \beta$ was added. As control, cells received an equal concentration of corresponding sense oligonucleotides or the same medium without oligonucleotides. Cell counts were performed over a period of $6 \mathrm{~d}$, with two replicate samples for each time point.
Electrophoretic mobility shift assay (EMSA). Adherent cells $\left(\geq 10^{6}\right)$ were grown in 10-cm plastic tissue culture dishes, rested for $6 \mathrm{~h}$ in SFM, and then incubated for $30 \mathrm{~min}$ in SFM with or without cytokine, washed, and harvested by scraping with a rubber policeman. Whole cell, cytoplasmic, and nuclear extracts were prepared and EMSAs were performed on $4 \%$ native polyacrylamide gels as described (27, 28). For supershift experiments, extracts were preincubated with Stat $1 \alpha$ polyclonal antibody (C-24; Santa Cruz Biotechnology, Santa Cruz, CA) or Stat $3 \alpha$ polyclonal antibody (C-20, Santa Cruz Biotechnology).

Immunoblotting. Whole cell extracts were mixed with $2 \times$ sodium dodecyl sulfate (SDS) sample buffer $(125 \mathrm{mmol} / \mathrm{L}$ Tris-HCL, $\mathrm{pH} 6.8$; $4 \%$ SDS; $20 \%$ glycerol; $10 \%$ 2-mercaptoethanol) at 1:1 ratio and were heated for $5 \mathrm{~min}$ at $100^{\circ} \mathrm{C}$. Proteins $(50 \mu \mathrm{g} / \mathrm{lane})$ were separated by $12.5 \%$ SDS-PAGE and transferred onto a nitrocellulose membrane (MSI; Westboro, MA). Prestained molecular weight markers (GIBCO BRL; Gaithersburg, MD) were included in each gel. Membranes were blocked for $30 \mathrm{~min}$ in Tris-buffered saline (TBS: 10 $\mathrm{mmol} / \mathrm{L}$ Tris-HCL, pH 7.5 and $150 \mathrm{mmol} / \mathrm{L} \mathrm{NaCl}$ ) with $0.5 \%$ Tween20 (TBST) and 5\% BSA. After blocking, membranes were incubated with a primary antibody; mouse anti-human Stat1 or Stat 3 monoclonals (Transduction Labs, Lexington, KY), a rabbit polyclonal antiHA-probe (Y-11) (Santa Cruz Biotechnology) or a phosphospecific

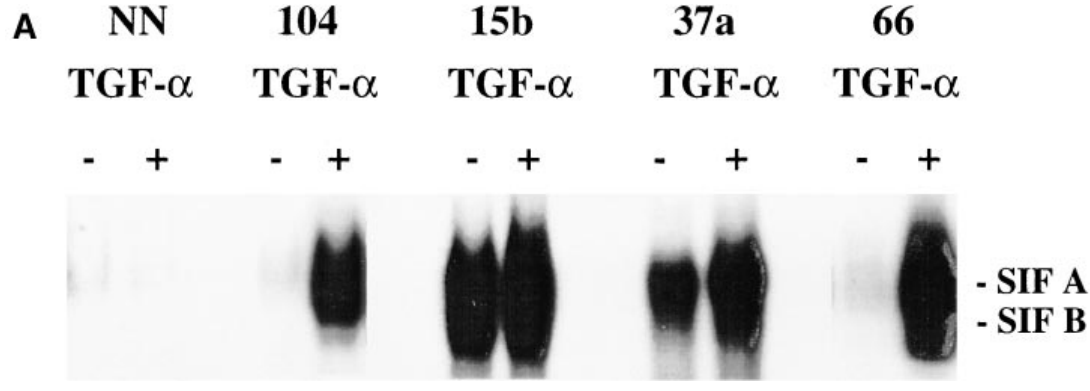

B

TGF- $\alpha$ anti-Stat 1 anti-Stat 3

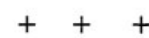

$+\quad+$

$-\quad+$
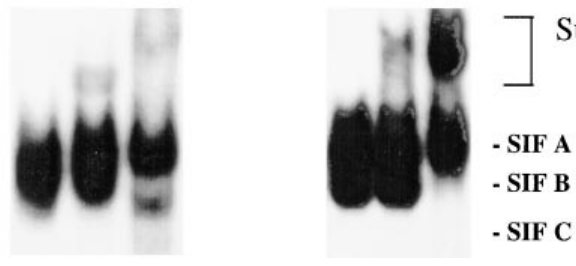

Supershifted complex

- Stat $3 \alpha$

- Stat $3 \beta$

- Stat1 $\alpha$

- Stat $1 \beta$
Figure 1. Constitutive and TGF- $\alpha$-stimulated hSIE-binding activation. $(A)$ Whole cell extracts $(20 \mu \mathrm{g})$ were prepared from head and neck cancer cell lines (clone name indicated by number; SCC 66 kindly provided by Suzanne Gollin) and normal mucosal epithelial cells that were untreated or treated with TGF- $\alpha(30 \mathrm{ng} / \mathrm{ml})$ for $30 \mathrm{~min}$. EMSA was performed $(26,27)$ with radiolabeled $\mathrm{hSIE}$ duplex oligonucleotide (21). The position of the SIF-A complex (Stat3 homodimer), SIF-B complex (Stat1/Stat3 heterodimer), and SIF-C complex (Stat1 homodimer) are indicated on the right. $(B)$ EMSA was performed using whole cell extracts of a representative SCCHN cell line (PCI $15 b)$ before and after stimulation with TGF- $\alpha$ (30 $\mathrm{ng} / \mathrm{ml}$ for $30 \mathrm{~min}$ ). Extracts were preincubated with rabbit antibody to Stat $1 \alpha(\mathrm{C}-24)$ or Stat $3 \alpha$ (C-20) or no antibody as indicated. The position of the SIF-A, -B, and -C complexes and the supershifted complexes are indicated on the right. $(C)$ Whole cell extracts prepared from untreated or TGF- $\alpha$-treated $(30 \mathrm{ng} / \mathrm{ml})$ cells (PCI-15b) $(27,28)$ were mixed with salmon sperm DNA $(500 \mathrm{mg} / \mathrm{ml})$ followed by incubation for $40 \mathrm{~min}$ with streptavidin-conjugated paramagnetic beads (Dynabead M280 streptavidin, Dynal) to which biotinylated tandem hSIE duplex oligonucleotides had previously been bound. Proteins were eluted with high salt buffer (17). After separation by SDS-PAGE, proteins were blotted onto PVDF membrane, and probed with Stat 3 antibody (top) or Stat1 antibody (bottom). The position of the Stat $3 \alpha$ and $\beta$ bands and Stat $1 \alpha$ and $\beta$ bands are indicated on the right. 
anti-Stat3 pTYR $^{705}$ rabbit polyclonal (Quality Controlled Biochemicals; Hopkington, MA) in TBST and $1 \%$ BSA. After washing the membranes three times with TBST ( 5 min each), they were incubated with horseradish peroxidase-conjugated secondary antibody in TBST and $1 \%$ BSA for $30 \mathrm{~min}$. Subsequently, membranes were washed three times with TBST and developed using the enhanced chemiluminescence (ECL) detection system (Amersham Life Sciences Inc.; Arlington Heights, IL).

DNA-binding affinity purification. Whole cell extracts were prepared from TGF- $\alpha$-stimulated and -unstimulated cells using a high salt buffer as described $(28,29)$. The whole cell extracts were mixed with salmon sperm DNA $(500 \mu \mathrm{g} / \mathrm{mL})$ and incubated at $4^{\circ} \mathrm{C}$ for 10 min. This mixture was incubated at $4^{\circ} \mathrm{C}$ for 40 min more with streptavidin-conjugated paramagnetic beads (Dynabead M280 streptavidin; Dynal Inc., Lake Success, NY), to which biotinylated tandem hSIE duplex oligonucleotides had previously been bound. After this incubation, the beads were washed five times with high salt buffer containing $0.05 \% \mathrm{NP}-40$ and $200 \mu \mathrm{g} / \mathrm{mL}$ salmon sperm DNA. Proteins were eluted with high salt buffer containing $1.2 \mathrm{~mol} / \mathrm{L} \mathrm{NaCl}$ as described (17). The Stat 3 antibody used was directed against the aminoterminal portion of the protein (amino acids 1-175; Transduction Labs).

Transfection of SCCHN cells with dominant negative Stat 3 and Stat1 constructs. Plasmids expressing hemagglutinin peptide (HA)tagged mutant Stat3 (phenylalanine substitution at Tyr705) (Stat3F) or mutations at the positions important for DNA binding (Stat3D), or Stat1 (Phe substitution for Tyr701) (Stat1F) containing an internal neomycin resistance marker were kindly provided by Dr. T. Hirano (Osaka University Medical School, Suita, Japan) (30) and stably transfected into several SCCHN cell lines using G418 selection media (400 $\mu \mathrm{g} / \mathrm{ml})$. Several (3-5) clones from each construct were isolated from each cell line using a cloning ring, were expanded, and EMSA was performed to determine that the incorporated mutant Stat protein functioned in a dominant negative fashion as previously described (30). Growth rates of individual clones were determined by erythrosin B dye exclusion at four time points.

\section{Results}

STAT activation/expression in SCCHN cells. To determine whether STAT proteins may be intracellular candidates linking upregulation of TGF- $\alpha$ and EGFR to increased proliferation of transformed squamous epithelial cells, we examined constitutive and TGF- $\alpha$-stimulated activation of STATs 1 and 3 in a series of SCCHN cell lines. EMSAs of whole cell and nuclear extracts from head and neck cancer cells using the high affinity serum-inducible element (hSIE) revealed varying degrees of constitutive activation of an hSIE-binding activity in all seven SCCHN cell lines examined compared with normal mucosal epithelial cells. The predominant complexes formed were SIF-A (Stat3 homodimer) and SIF-B (Stat3 and Stat1 heterodimer). Further activation of SIF-A and SIF-B complexes were observed after stimulation with $\mathrm{TGF}-\alpha$ where dose-response studies suggested that maximum activation was achieved with $30 \mathrm{ng} / \mathrm{ml}$ of exogenous TGF- $\alpha$ for $30 \mathrm{~min}$. (Fig. 1 $A$ and data not shown). To verify that the constitutive and activatable SIF-A and SIF-B complexes contained Stat 3 and Stat1, we performed supershift analysis (Fig. $1 B$ ) and DNA-affinity purification studies (Fig. $1 C$ ), which revealed constitutive and TGF- $\alpha$-stimulated activation of Stat1 and Stat 3 in SCCHN cell lines.

To determine whether the increase in constitutive STAT activation was associated with increased protein expression, we performed immunoblotting studies using antisera to Stat1 or Stat3. These experiments demonstrated an increase in Stat3
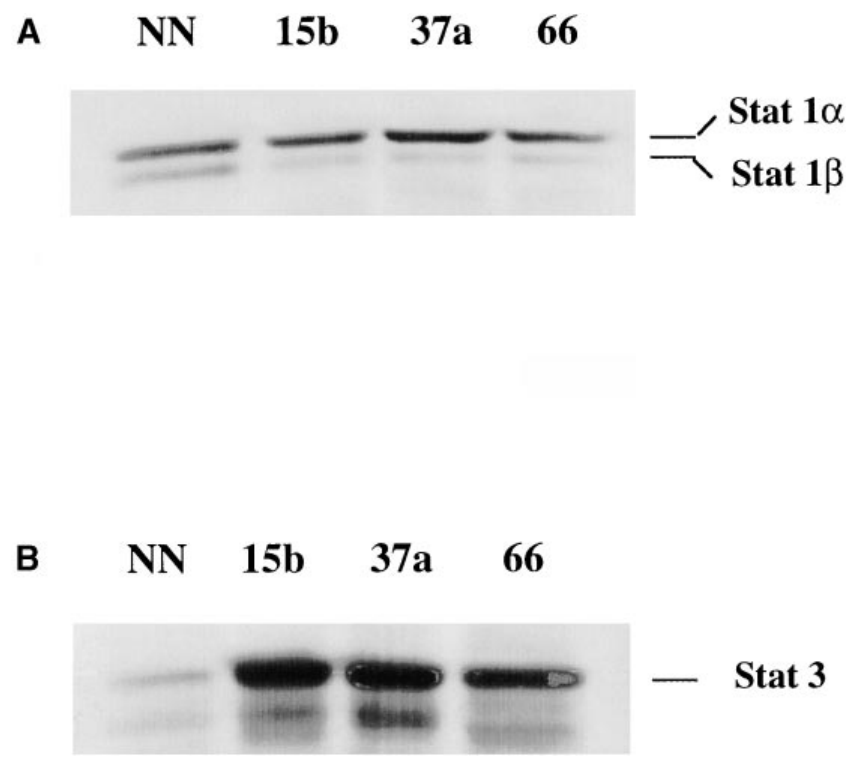

Figure 2. Stat1 and Stat3 protein expression levels. (A) Stat $1 \mathrm{immu-}$ noblotting of protein extracts $(50 \mu \mathrm{g})$ from normal mucosal epithelial cells and representative head and neck cancer cell lines. (B) Stat3 immunoblotting of same cell extracts.

protein expression levels in head and neck cancer cell lines compared with normal mucosal epithelial cells. In contrast, Stat 1 protein levels in head and neck squamous cell carcinoma cell lines were comparable to those detected in corresponding normal cells (Fig. 2). Phosphotyrosine immunoblotting was performed to determine whether the increased Stat 3 expression/activation detected was associated with elevated tyrosine phosphorylation. These results demonstrated that Stat3 tyrosine phosphorylation in head and neck cancer cells is elevated compared to levels detected in normal mucosal epithelial cells (Fig. 3).

Stat 3 activation is linked to $T G F-\alpha / E G F R$ signaling. To verify that the constitutive Stat3 activation detected was a result of EGFR signaling, we biochemically targeted the EGFR using a specific tyrosine kinase receptor (PD153035), which we've previously demonstrated to inhibit EGFR kinase activity and cell growth in head and neck cancer cells (6). After exposure to PD153035 (20 nM), EMSAs of whole cell extracts revealed decreased constitutive Stat 3 activation (Fig. $4 A$ ). This diminution of Stat 3 activation by the EGFR-specific tyrosine kinase inhibitor was accompanied by decreased receptor phosphorylation as determined by immunoprecipitation followed by immunoblotting with antiphosphotyrosine antibody (data not shown). To determine whether TGF- $\alpha$ was the ligand in this tumor system linking EGFR to Stat3, we incubated head and neck cancer cells with a TGF- $\alpha-$ neutralizing

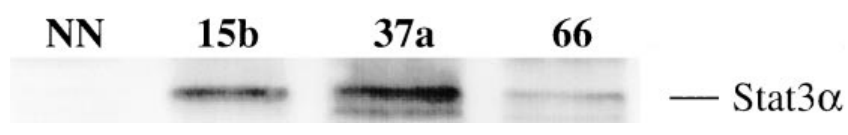

Figure 3. Stat3 tyrosine phosphorylation. Immunoblotting of protein extracts $(50 \mu \mathrm{g})$ from unstimulated normal mucosal epithelial cells and representative head and neck cancer cell lines using a phosphospecific anti-Stat 3 p-TYR ${ }^{705}$ antibody. The position of the phosphorylated Stat $3 \alpha$ protein is indicated on the right. 

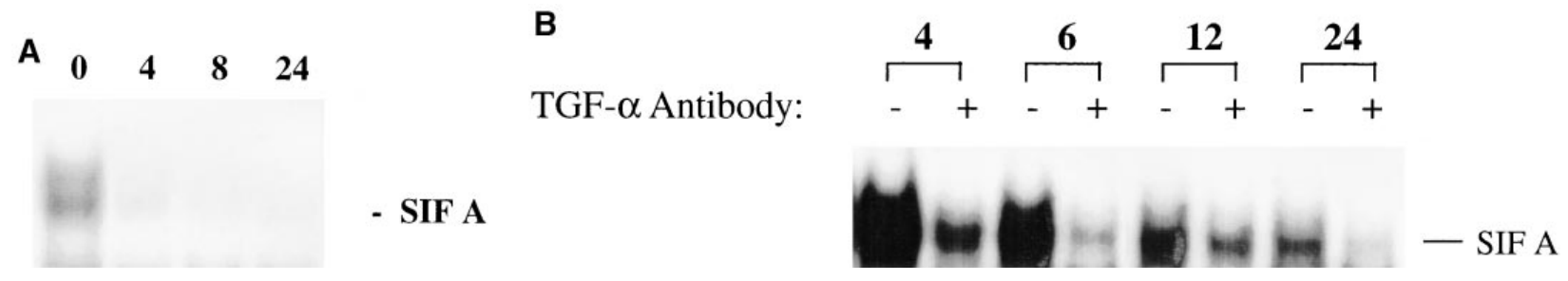

Figure 4. Stat3 activation associated with TGF- $\alpha$ /EGFR signaling. $(A)$ Inhibition of Stat 3 activation by an EGFR-specific tyrosine kinase inhibitor. EMSA analysis of unstimulated whole cell extracts of a representative SCCHN cell line (PCI 37a) before, and at several time points (hours) after treatment with an EGFR-specific tyrosine kinase inhibitor (PD153035; $20 \mathrm{nM})$ (22). The position of the SIF-A complex is indicated on the right. (B) Inhibition of Stat3 activation by a TGF- $\alpha$-neutralizing antibody. EMSA analysis of unstimulated whole cell extracts of a representative SCCHN cell line (PCI 37a) before, and at several time points (hours) after treatment with a TGF- $\alpha-$ neutralizing antibody (7.5 $\mu \mathrm{g} / \mathrm{ml}$ ). The position of the SIF-A complex is indicated on the right.

antibody $(7.5 \mathrm{mg} / \mathrm{ml})$ and demonstrated decreased Stat 3 activation, which was rapidly detected and persisted for $24 \mathrm{~h}$ (Fig. $4 B)$.

Requirement of Stat3, but not Stat1 for SCCHN proliferation. To determine whether the constitutive activation of Stat3 was important for the growth of SCCHN cells, several SCCHN cell lines were stably transfected with dominant nega-

\section{A}

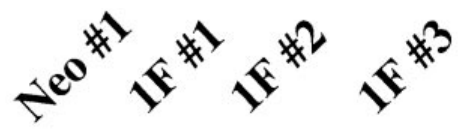

B

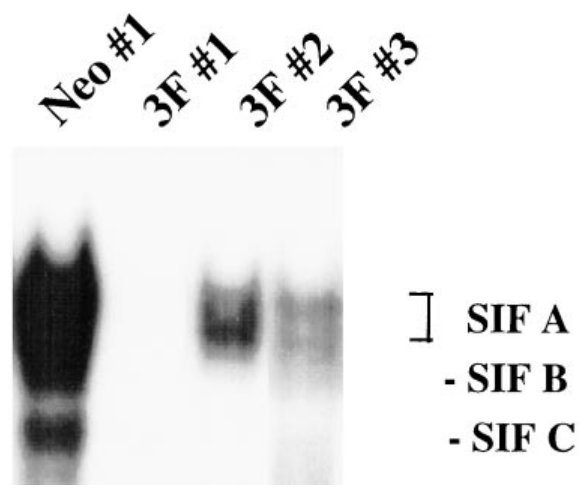

Figure 5. Inhibition of Stat1 and Stat 3 activation by dominant-negative mutants in a representative head and neck cancer cell line (PCI 15b). (A) Whole cell extracts of unstimulated representative dominant negative Stat1 clones and a neomycin control-transfected clone were analyzed by EMSA using the Stat1 GAS duplex oligonucleotide (21). (B) Whole cell extracts of unstimulated representative dominant negative Stat 3 clones and a neomycin control-transfected clone were analyzed by EMSA using hSIE duplex oligonucleotide. The position of the SIF-A, -B, and -C complexes are indicated on the right. tive Stat 3 mutant constructs $(3 \mathrm{~F}$, where tyrosine 705 in Stat 3 is replaced by phenylalanine; $3 \mathrm{D}$, where mutations were inserted at positions important for DNA binding [glutamic acid 434 and glutamic acid 435 were replaced with alanines]). In addition, the same cell lines were transduced with a dominant negative Stat1 mutant construct $(1 \mathrm{~F}$, where tyrosine 701 in Stat1 is replaced by phenylalanine) to determine the importance of Stat 1 for cell growth (30). Isolated clones were analyzed by EMSA to demonstrate that the transfected mutant protein functioned to decrease Stat1 or Stat 3 activity (Fig. 5). Growth rates were determined of several individual clones from three representative SCCHN cell lines transfected with either of the two mutant Stat 3 constructs, or the mutant Stat 1 construct, or the neomycin-containing control vector (Fig. 5). Immunoblotting using a Stat 3 phosphotyrosine antibody demonstrated reduced protein expression in cells stably transfected with the mutant Stat 3 constructs (Fig. 6 and data not shown). In all cases, clones expressing either mutant form of Stat3 (3F or 3D) failed to proliferate, compared with neomycin control-transfected cells. By contrast, the same cells stably transfected with the mutant Stat1 construct demonstrated no reduction in proliferation (Fig. 7). In one cell line (SCC 66), despite repeated transfections, we were able to isolate only a single clone transduced with one of the Stat 3 mutant constructs $(3 \mathrm{~F})$. All other clones, which were initially isolated, failed to proliferate beyond a few cells (data not shown). However, if Stat3 activation is critical for proliferation, in some instances cells stably transfected with the dominant negative mutant Stat 3 will then fail to grow in vitro. To overcome this potential obstacle and confirm the results using dominant-negative constructs, we designed phosphorothioated antisense oligonucleotides targeting the translation start sites of Stat1 or Stat 3 messenger RNA. Dose-response experiments revealed that $12.5 \mu \mathrm{M}$ of antisense oligonucleotide resulted in

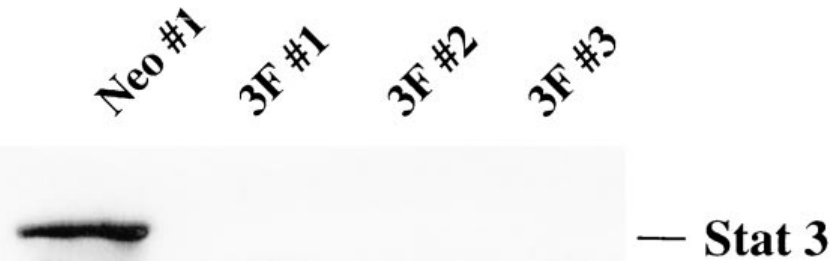

Figure 6. Stat 3 tyrosine phosporylation in dominant negative clones. Immunoblotting of protein extracts $(50 \mu \mathrm{g})$ from a representative unstimulated neo-transfected control clone and Stat 3 dominant negative clones (3F construct; PCI 15b cell line). 


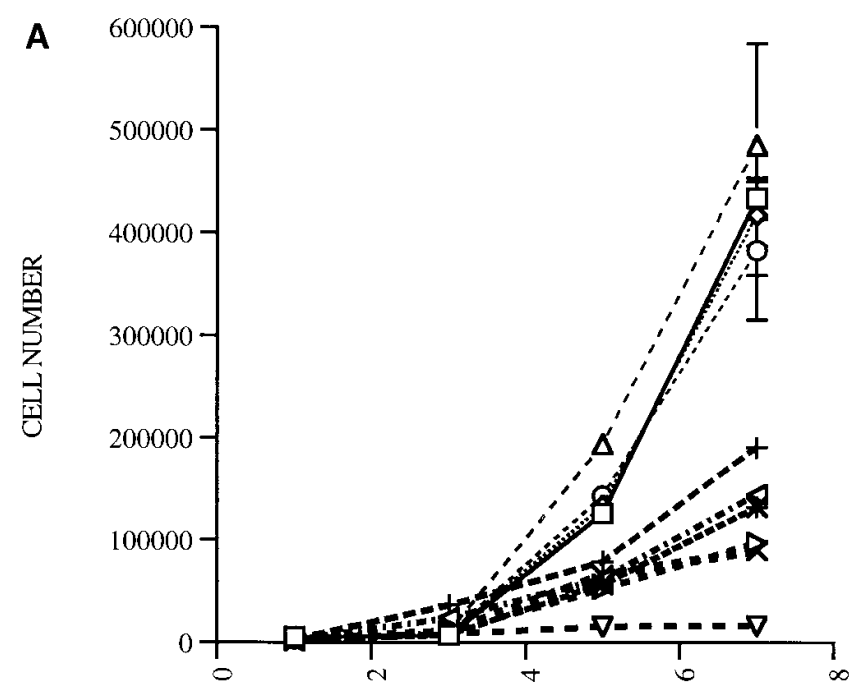

DAY

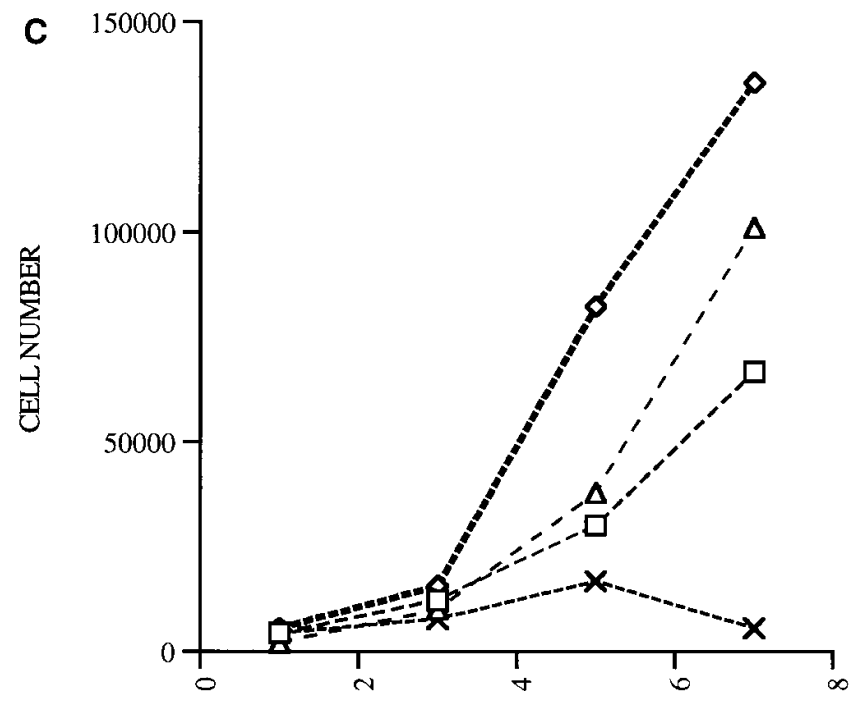

DAY

maximum growth inhibition with minimal added antiproliferative effect using higher doses (data not shown). Incubation of three representative cell lines with Stat 3 antisense oligonucleotides consistently resulted in significant growth inhibition (Table I). In contrast, treatment of the same cell lines with Stat1 antisense oligonucleotides failed to result in reduced proliferation (Fig. 8 and data not shown). After treatment with the antisense oligonucleotides, EMSA analysis was performed which demonstrated decreased activation of the targeted STAT protein (Fig. 9 and data not shown).

\section{Discussion}

EGFR (HER1) is a member of the Type 1 tyrosine kinase family of cell surface receptors (7). Putative ligands for EGFR

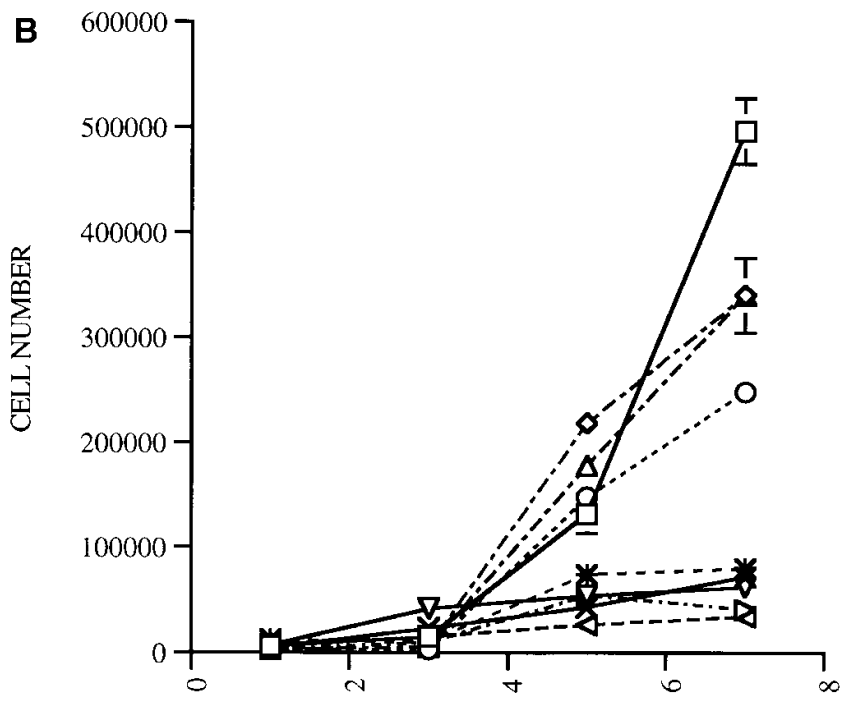

DAY

Figure 7. Inhibition of proliferation of Stat3-dominant negative but not Stat1-dominant negative clones. $(A)$ Clones derived from PCI $15 \mathrm{~b}$ cell line, $(B)$ from PCI 37 a cell line, or $(C)$ from SCC 66 cell line. Cell counts of clones from representative SCCHN cell lines stably transfected with Stat3F-DN (x, _, + ), Stat3D-DN $\left(*,{ }_{-},{ }_{-}\right)$, Stat1-DN $(\diamond, \bigcirc, \triangle)$, or neomycin-resistance marker alone $(\square)$ were performed at serial time points by vital dye exclusion.

include EGF, TGF- $\alpha$, amphiregulin, heparin-binding EGF, and CRIPTO. Head and neck cancer cells do not express EGF and amphiregulin or CRIPTO are expressed at levels similar to those detected in normal mucosal epithelial cells (J. Rubin

Table I. Mean Percent Inhibition with Antisense (versus Sense) Oligonucleotides Targeting STATs 1 and 3

\begin{tabular}{lrrrrrr}
\hline & \multicolumn{2}{c}{ Stat 1} & & \multicolumn{2}{c}{ Stat 3 } & \\
\cline { 2 - 3 } $\begin{array}{l}\text { SCCHN } \\
\text { Cell line }\end{array}$ & Sense & Antisense & & Sense & Antisense & $\begin{array}{c}P \\
\text { Value }\end{array}$ \\
\hline $15 \mathrm{~b}$ & 12.3 & 12.9 & & - & 31.2 & 0.02 \\
$37 \mathrm{a}$ & 16.4 & 1.6 & & 7.5 & 59.2 & 0.003 \\
66 & 15.3 & 10.6 & & 11.1 & 78.9 & 0.002 \\
& & & & & & \\
\hline
\end{tabular}




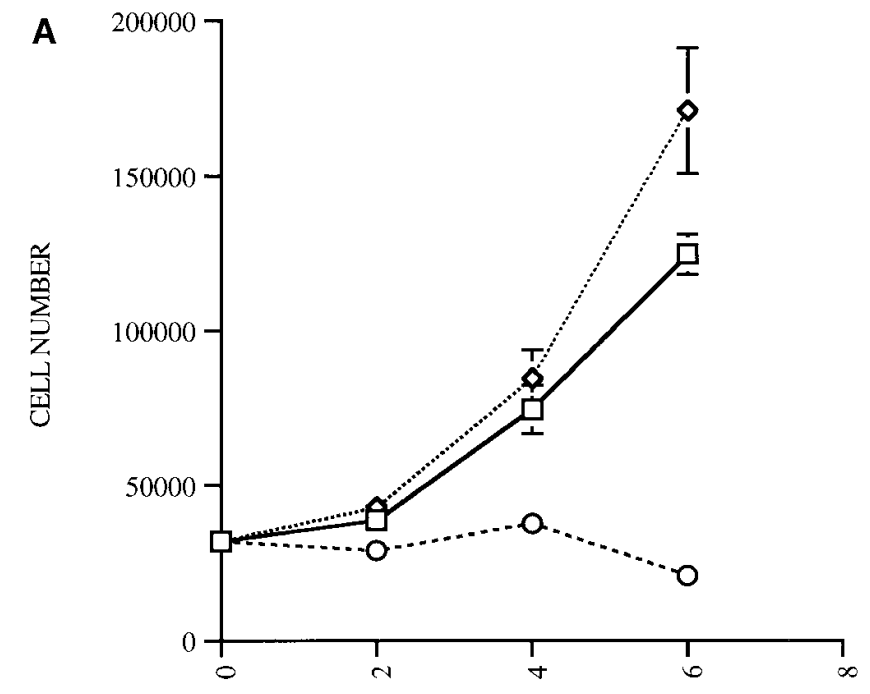

DAYS

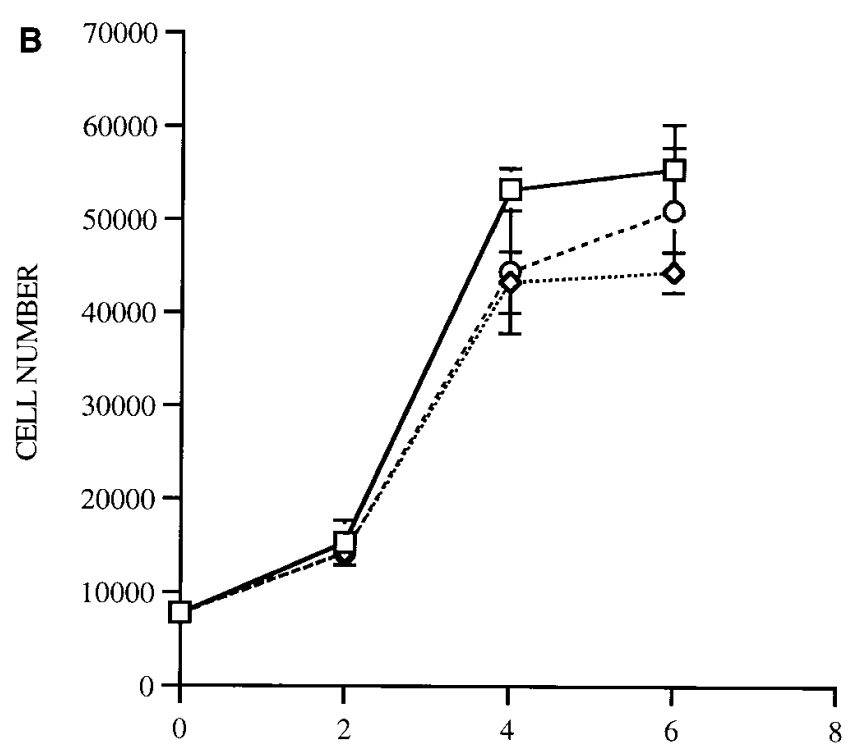

DAYS

Figure 8. Phosphorothioated antisense oligonucleotide treatment of SCCHN cells targeting Stat1 and Stat3. (A) Cells (PCI 15b) treated with $12.5 \mu \mathrm{M}$ Stat 3 antisense oligonucleotides $(\bigcirc)$ demonstrated significant growth inhibition compared with cells treated with the corresponding sense oligonucleotide $(\diamond)(P=0.02)$ or no oligonucleotide $(\square)$. (B) The same cell line treated with Stat1 antisense oligonucleotides $(\bigcirc)$, sense oligonucleotides $(\diamond)$, or no oligonucleotide $(\square)$.

Grandis, unpublished observations). Overexpression of TGF- $\alpha$ and EGFR (mRNA and protein) has been detected in tumors and cell lines established from patients with head and neck cancer $(31,32)$, and elevated levels of TGF- $\alpha$ and/or EGFR have been associated with adverse clinical outcome (33-35). We recently reported that TGF- $\alpha$ or EGFR protein levels in the primary head and neck squamous cell carcinoma were significant predictors of decreased survival, independent of re-

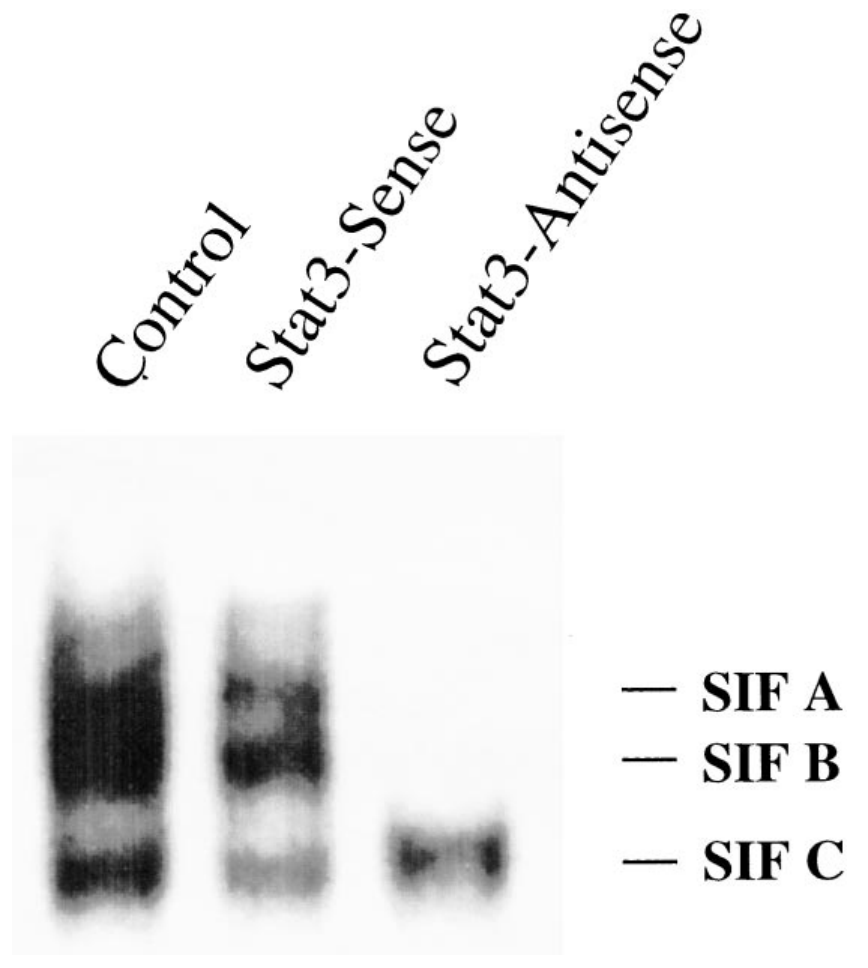

Figure 9. EMSA of whole cell extracts from representative head and neck cancer cells (PCI 15b) after $3 \mathrm{~d}$ of treatment with Stat 3 antisense oligonucleotides $(12.5 \mu \mathrm{M})$, or corresponding sense oligonucleotides $(12.5 \mu \mathrm{M})$, or no oligobucleotides (Control) performed with radiolabeled duplex hSIE oligonucleotide.

gional lymph node staging (36). In vitro studies targeting either ligand or receptor resulted in the inhibition of transformed but not normal mucosal epithelial cell proliferation (6, $24)$, indicating that TGF- $\alpha$ and EGFR are participating in an autocrine growth pathway in transformed squamous epithelial cells.

Activation of EGFR by ligands (including TGF- $\alpha$ ) leads to activation of a variety of signaling molecules. To date, targeting of these downstream intermediates (e.g., ras, MAP kinase, PI-3-kinase, PLC $\gamma$ ) has not been reported to inhibit the proliferation of cells that overexpress EGFR. STAT proteins have been demonstrated to serve as critical intracellular mediators after ligand activation in a wide range of peptide ligand-receptor systems $(37,38)$. Antisense oligonucleotides directed against Stat1 have been reported to abrogate growth factorinduced mitogenesis in non-transformed liver epithelial cells (39). However, only a few reports demonstrate an association between STATs and cancer. Whereas EGF has been shown to be capable of activating STATs 1 and 3 in EGFR-overexpressing cells $(25,38,40-44)$, STAT activation in these cells has not been linked to proliferation or transformation. Recent studies demonstrate that Src-induced transformation of fibroblasts results in Stat3-mediated gene expression (45) and that Stat3 is constitutively activated in breast carcinoma cell lines but not in normal breast epithelial cells (46). The results presented here are the first demonstration of growth inhibition after selective downmodulation of a STAT protein in EGFR-overexpressing cells. Cells stably transfected with either of two mutant forms of Stat 3 demonstrated decreased constitutive Stat 3 activation, reduced expression of phosphorylated Stat3 protein, and failed 
to proliferate, suggesting that Stat 3 is critical for the growth of head and neck cancer cells. Targeting constitutively activated Stat 1 and Stat 3 with dominant-negative mutant constructs or antisense oligonucleotides in head and neck cancer cells resulted in differential effects on proliferation. Abrogation of constitutive Stat 3 activation was associated with reduced proliferation, whereas downmodulation of Stat1 had no effect on the growth rate of carcinoma cells. These results suggest that endogenously produced TGF- $\alpha$ activates Stat 3 via EGFR signaling, which, in turn, stimulates the transcription of genes resulting in aberrant squamous epithelial cell proliferation characteristic of the transformed phenotype.

The level of constitutive and TGF- $\alpha$-inducible STAT activation varied somewhat among the head and neck cancer cell lines examined. We have previously determined that although head and neck squamous cell carcinoma cell lines all overexpress TGF- $\alpha$ and EGFR when compared with normal mucosal epithelial cells, there is a range of mRNA and protein levels detected $(6,24)$. Because Stat 3 is activated in response to TGF- $\alpha /$ EGFR interaction, the relative amounts of TGF- $\alpha$ produced by the tumor cell and the number of EGF receptors on the cell surface may contribute to the level of constitutive STAT activation detected. Our results demonstrate that in comparison with normal mucosal epithelial cells, Stat 3 protein is overexpressed in head and neck cancer cells. In addition, these transformed squamous epithelial cells demonstrate elevated Stat 3 tyrosine phosphorylation levels compared to those detected in normal mucosal epithelial cells. These results suggest that increased protein expression and tyrosine phosphorylation are associated with increased constitutive activation of Stat3. Although not specifically examined, the possibility of a mutation in Stat 3 in head and neck cancer cells cannot be excluded.

\section{Acknowledgments}

This study was supported in part by the John R. McCune Charitable Trust Foundation, the Mary Hillman Jennings Foundation, The Smokeless Tobacco Research Council, and grants CA01760 (J. Rubin Grandis), CA72526 (J. Rubin Grandis), and CA 72261 (D.J. Tweardy) from the National Cancer Institute.

\section{References}

1. Todd, R., B.R. Donoff, R. Gertz, A.L. Chang, P. Chow, K. Matossian, J. McBride, T. Chiang, G.T. Gallagher, and D.T. Wong. 1989. TGF- $\alpha$ and EGF receptor mRNA in human oral cancers. Carcinogenesis. 10:1553-1556.

2. Rubin Grandis, J., and D.J. Tweardy. 1993. Elevated levels of transforming growth factor $\alpha$ and epidermal growth factor receptor messenger RNA are early markers of carcinogenesis in head and neck cancer. Cancer Res. 53:3579-3584.

3. Rubin Grandis, J., M.F. Melhem, E.L. Barnes, and D.J. Tweardy. 1996. Quantitative immunohistochemical analysis of transforming growth factor- $\alpha$ and epidermal growth factor receptor in patients with squamous cell carcinoma of the head and neck. Cancer. 78:1284-1292.

4. Moroni, M.C., M.C. Willingham, and L. Bequinot. 1992. EGF-R antisense RNA blocks expression of the epidermal growth factor receptor and suppresses the transforming phenotype of a human carcinoma cell line. J. Biol. Chem. 267:2714.

5. Nicolini, G., M. Moloso, M.C. Moroni, L. Bequinot, and L. Scotto. 1996. Post-transcriptional control regulates transforming growth factor- $\alpha$ in the human carcinoma KB cell line. Biol. Chem. 271:30290-30296.

6. Rubin Grandis, J., A. Chakraborty, M.F. Melhem, Q. Zeng, and D.J. Tweardy. 1997. Inhibition of epidermal growth factor receptor gene expression and function decreases proliferation of head and neck squamous carcinoma but not normal mucosal epithelial cells. Oncogene. 15:409-416.

7. Ulrich, A., and J. Schlessinger. 1990. Signal transduction by receptors with tyrosine kinase activity. Cell. 61:203-212.
8. Hernandez-Sotomayor, S.M.T., and G. Carpenter. 1992. Epidermal growth factor receptor: elements of intracellular communication. Membr. Biol. 128:81-89.

9. Kumar, V., S.A. Bustin, and I.A. McKay. 1995. Transforming growth factor $\alpha$. J. Cell. Biol. Int. 19:373-388.

10. Ihle, J.N., and I.M. Kerr. 1995. Jaks and Stats in signaling by the cytokine receptor superfamily. Trends Genet. 11:69-74.

11. Ivanshkiv, L.B. 1995. Cytokines and STATs: how can signals achieve specificity? Immunity. 3:1-4.

12. Yu, C.L., D.J. Meyer, G.S. Campbell, A.C. Larner, C. Carter-Su, J. Schwartz, and R. Jove. 1995. Enhanced DNA-binding activity of a Stat-3related protein in cells transformed by the Src oncoprotein. Science. 269:81.

13. Cao, X., A. Tay, G.R. Guy, and Y.H. Tan. 1996. Activation and association of Stat3 with Src in v-Src-transformed cell lines. Mol. Cell. Biol. 16:1595-1603.

14. Zong, C., R. Yan, A. August, J.E. Darnell, Jr., and H. Hanafusa. 1996. Unique signal transduction of Eyk: constitutive stimulation of the JAK-STAT pathway by an oncogenic receptor-type tyrosine kinase. EMBO (Eur. Mol. Biol. Organ.) J. 15:4515-4525.

15. Watson, C.J., and W.R. Miller. 1995. Elevated levels of members of the STAT family of transcription factors in breast carcinoma nuclear extracts. $B r . J$. Cancer. 71:840-844.

16. Sartor, C.I., M.L. Dziubinski, C.L. Yu, R. Jove, and S.P. Ethier. 1997. Role of epidermal growth factor receptor and STAT-3 activation in autonomous proliferation of SUM-102PT human breast cancer cells. Cancer Res. 57: 978-987.

17. Chakraborty, A., S.M. White, T.S. Schaefer, E.D. Ball, K.F. Dyer, and D.J. Tweardy. 1996. Granulocyte colony-stimulating factor activation of Stat $3 \alpha$ and Stat $3 \beta$ in immature normal and leukemic human myeloid cells. Blood. 88 : 2442-2449.

18. Saachi, M., C.H. Snyderman, D.S. Heo, J.T. Johnson, F. D’Amico, R.B Herberman, and T.L. Whiteside. 1990. Local adoptive immunotherapy of human head and neck cancer xenografts in nude mice with lymphokine-activated killer cells and interleukin 2. Cancer Res. 50:3113-3118.

19. Heo, D.S., S.M. Snyderman, S.M. Gollin, S. Pan, E. Walker, R. Deka, E.L. Barnes, J.T. Johnson, R.B. Herberman, and T.L. Whiteside. 1989. Biology, cytogenetics and sensitivity to immunological effector cells of new head and neck squamous cell carcinoma lines. Cancer Res. 49:5167-5175.

20. Baumann, H., D. Gearing, and S.F. Ziegler. 1994. Signaling by the cytoplasmic domain of hematopoietin receptors involves two distinguishable mechanisms in hepatic cells. J. Biol. Chem. 269:16297-16304.

21. Rubin Grandis, J., Q. Zeng, and D.J. Tweardy. 1996. Retinoic acid normalized the increased gene transcription rate of TGF- $\alpha$ and EGFR in head and neck cancer. Nat. Med. 2:237-240.

22. Tweardy, D.J., T.M. Wright, S.F. Ziegler, H. Baumann, A. Chakraborty, S.M. White, K.F. Dyer, and K.A. Rubin. 1995. Granulocyte colony-stimulating factor rapidly activated a distinct STAT-like protein in normal myeloid cells. Blood. 86:4409-4416.

23. Fry, D.W., A.J. Kraker, A. McMichael, L.A. Ambroso, J.M. Nelson, W.R. Leopold, R.W. Connors, and A.J. Bridges. 1994. A specific inhibitor of the epidermal growth factor receptor tyrosine kinase. Science. 265:1093-1095.

24. Rubin Grandis, J., A. Chakraborty, Q. Zeng, M.F. Melhem, and D.J. Tweardy. 1998. Downmodulation of TGF- $\alpha$ protein expression with antisense oligonucleotides inhibits proliferation of head and neck squamous carcinoma but not normal mucosal epithelial cells. J. Cell. Biochem. 68:1-8.

25. Zhong, Z., Z. Wen, and J.E. Darnell, Jr. 1994. Stat3: A STAT family member activated by tyrosine phosyphorylation in response to epidermal growth factor and interleukin-6. Science. 264:95.

26. Schindler, C., X.Y. Fu, T. Improta, R. Aebersold, and J.E. Darnell, Jr. 1992. Proteins of transcription factor ISGF-3: one gene encodes the 91- and 84kD ISGF-3 proteins that are activated by interferon $\alpha$. Proc. Natl. Acad. Sci. USA. 89:7836-7839.

27. Sadowski, H.B., K. Shuai, J.E. Darnell, Jr., and M.Z. Gilman. 1993. A common nuclear signal transduction pathway activated by growth factor and cytokine receptors. Science. 261:1739.

28. Wong, P., C.W. Severns, N.B. Guyer, and T.M. Wrights. 1994. A unique palindromic element mediates $\gamma$-interferon induction of mig gene expression. Mol. Cell. Biol. 14:914.

29. Wagner, B.J., T.E. Hayes, C.J. Hoban, and B.H. Cochran. 1990. The SIF-binding element confers sis/PDGF inducibility onto the c-fos promoter. EMBO (Eur. Mol. Biol. Organ.) J. 9:4477.

30. Nakajima, K., Y. Yamanaka, K. Nakae, H. Kojima, M. Ichiba, N. Kiuchi, T. Kitaoka, T. Fudada, M. Hibi, and T. Hirano. 1996. A central role for Stat 3 in IL-6-induced regulation of growth and differentiation in M1 leukemia cells. EMBO (Eur. Mol. Biol. Organ.) J. 15:3651-3658.

31. Kawamoto, T., K. Takahashi, M. Nishi, T. Kimura, T. Matsumura, and S. Taniguchi. 1991. Quantitative assay of epidermal growth factor receptor in human squamous cell carcinomas of the oral region by an avidin-biotin method. Jpn. J. Cancer Res. 82:403-410.

32. Christensen, M.E., M.H. Therkildsen, B.L. Hansen, H. Albeck, G.N. Hansen, and P. Bretlau. 1992. Epidermal growth factor receptor expression on oral mucosa dysplastic epithelia and squamous cell carcinoma. Eur. Arch. Otorhino-laryngol. 249:243-247. 
33. Miyaguchi, M., J. Olofsson, and H.B. Hellquist. 1991. Expression of epidermal growth factor receptor in glottic carcinoma and its relation to recurrence after radiotherapy. Clin. Otolaryngol. 16:466-469.

34. Maurizi, M., G. Scambia, and P. Benedetti Panice. 1992. EGF receptor expression in primary laryngeal cancer: correlation with clinic-pathological features and prognostic significance. Int. J. Cancer. 52:862-866.

35. Wen, W.H., T. Miwa, T. Yoshizaki, I. Nagayama, M. Furukawa, and H. Nishijima. 1996. Prognostic value of EGFR and TGF- $\alpha$ in early laryngeal cancer treated with radiotherapy. Laryngoscope. 106:884-888.

36. Rubin Grandis, J., M.F. Melhem, W.E. Gooding, R. Day, V.A. Holst, M.M. Wagener, S.D. Drenning, D.J. Tweardy. 1998. TGF- $\alpha$ and EGFR protein in head and neck squamous cell carcinoma and patient survival. J. Natl. Cancer Inst. 90:824-832.

37. Finidori, J., and P.A. Kelly. 1995. Cytokine receptor signaling through two novel families of transducer molecules: Janus kinases, and signal transducers and activators of transcription. J. Endocrinol. 147:11-23.

38. Leaman, D.W., S. Leung, X. Li, and G.R. Stark. 1996. Regulation of STAT-dependent pathways by growth factors and cytokines. FASEB (Fed. Am. Soc. Exp. Biol.) J. 10:1578-1588.

39. Marra, F., G.G. Choudhury, and H.E. Abboud. 1996. Interferon- $\gamma-$ mediated activation of STAT1 $\alpha$ regulates growth factor-induced mitogenesis. $J$. Clin. Invest. 98:1218-1230.

40. Sadowski, H.B., K. Shuai, J.E. Darnell, Jr., and M.Z. Gilman. 1993. A common nuclear signal transduction pathway activated by growth factor and cytokine receptors. Science. 261:1739.

41. Ruff-Jamison, S., K. Chen, and S. Cohen. 1995. Epidermal growth factor induces the tyrosine phosphorylation and nuclear translocation of Stat5 in mouse liver. Proc. Natl. Acad. Sci. USA. 92:4215-4218.

42. Park, O.K., T.S. Schaefer, and D. Nathans. 1996. In vitro activation of Stat3 by epidermal growth factor receptor kinase. Proc. Natl. Acad. Sci. USA. 93:13704-13708.

43. Chin, N., N. Nakamura, R. Kamiyama, N. Miyasaka, J.N. Ihle, and O. Miura. 1996. Physical and functional interactions between Stat5 and the tyrosine-phosyphorylated receptors for erythropoietin and interleukin-3. Blood. $88: 4415-4425$

44. Nakamura, N., N. Chin, N. Miyasaka, and O. Miura. 1996. An epidermal growth factor receptor/Jak2 tyrosine kinase domain chimera induces tyrosine phosphorylation of Stat5 and transduces growth signal in hematopoietic cells. $J$. Biol. Chem. 271:19483-19488.

45. Turkson, J., T. Bowman, R. Garcia, E. Caldenhoven, R.P. DeGroot, and R. Jove. 1998. Stat3 activation by Src induces specific gene regulation and is required for cell transformation. Mol. Cell. Biol. 18:2545-2552.

46. Garcia, R., C.L. Yu, A. Hudnall, R. Catlett, K.L. Nelson, T. Smithgall, D.J. Fugita, S.P. Ethier, and R. Jove. 1997. Constitutive activation of Stat 3 in fibroblasts transformed by diverse oncoproteins and in breast carcinoma cells. Cell Growth Differ. 8:1267-1276. 